\title{
Inhibitory Effects of Coptis japonica Alkaloids on the LPS-Induced Activation of BV2 Microglial Cells
}

\author{
Se Jin Jeon ${ }^{1, \#}$, Kyung Ja Kwon ${ }^{2, \#}$, Sunmi Shin ${ }^{1}$, Sung Hoon LeE ${ }^{1}$, So Young RHeE ${ }^{1}$, Seol-Heui HaN ${ }^{2}$, \\ Jongmin LEE ${ }^{2}$, Han Young KIM" ${ }^{2}$, Jae Hoon CHEONG ${ }^{3}$, Jong Hoon RYu ${ }^{4}$, Byung-Sun MIN ${ }^{5}$, \\ Kwang Ho Ko', and Chan Young SHIN ${ }^{2, *}$ \\ ${ }^{1}$ Department of Pharmacology, College of Pharmacy and research Institute of Pharmaceutical Sciences, \\ Seoul National University, Seoul 151-742, ${ }^{2}$ Center for Geriatric Neuroscience Research, IBST and School of Medicine, \\ Konkuk University, Seoul 143-701, ${ }^{3}$ Department of Pharmacy, Sahmyook University, Seoul 139-742, \\ ${ }^{4}$ Department of Oriental Pharmaceutical Science, College of Pharmacy, Kyung Hee University, Seoul 130-701, \\ ${ }^{5}$ College of Pharmacy, Catholic University of Daegu, Daegu 705-718, Republic of Korea
}

(Received December 15, 2008; Revised January 19, 2009; Accepted January 21, 2009)

\begin{abstract}
Coptis japonica (C. japonica) is a perennial medicinal plant that has anti-inflammatory activity. $C$. japonica contains numerous biologically active alkaloids including berberine, palmatine, epi-berberine, and coptisine. The most well-known anti-inflammatory principal in $C$. japonica is berberine. For example, berberine has been implicated in the inhibition of iNOS induction by cytokines in microglial cells. However, the efficacies of other alkaloids components on microglial activation were not investigated yet. In this study, we investigated the effects of three alkaloids (palmatine, epi-berberine and coptisine) from C. japonica on lipopolysaccharide (LPS)-induced microglial activation. BV2 microglial cells were immunostimulated with LPS and then the production of several inflammatory mediators such as nitric oxide (NO), reactive oxygen species (ROS) and matrix metalloproteinase-9 (MMP-9) were examined as well as the phosphorylation status of Erk1/2 mitogen activated protein kinase (MAPK). Palmatine and to a lesser extent epi-berberine and coptisine, significantly reduced the release of NO, which was mediated by the inhibition of LPS-stimulated mRNA and protein induction of inducible nitric oxide synthase (iNOS) from BV2 microglia. In addition to NO, palmatine inhibited MMP-9 enzymatic activity and mRNA induction by LPS. Palmatine also inhibited the increase in the LPS-induced MMP-9 promoter activity determined by MMP-9 promoter luciferase reporter assay. LPS stimulation increased Erk1/2 phosphorylation in BV2 cells and these alkaloids inhibited the LPS-induced phosphorylation of Erk1/2. The anti-inflammatory effect of palmatine in LPS-stimulated microglia may suggest the potential use of the alkaloids in the modulation of neuroinflammatory responses, which might be important in the pathophysiological events of several neurological diseases including Alzheimer's disease (AD), multiple sclerosis (MS), Parkinson's disease (PD) and stroke.
\end{abstract}

Keywords: Coptis japonica, Microglia, Nitric oxide (NO), Inducible nitric oxide synthase (iNOS), Matrixmetalloproteinase-9 (MMP-9)

\section{INTRODUCTION}

Microglia is a principle immune cell in the central nervous system (CNS) (Perry and Gordon, 1988). In response to brain injury, microglia is activated and secreted various

\footnotetext{
${ }^{*}$ Corresponding author

Tel: +82-2-2030-7834 Fax: +82-2-2049-6192

E-mail: chanyshin@kku.ac.kr

\#These authors equally contributed to this work.
}

cytoactive factors including reactive nitrogen species, reactive oxygen species, and inflammatory cytokines such as tumor necrosis factor- $\alpha$ (TNF- $\alpha$ ) (Cunningham et al., 2005; Majumdar et al., 2007). Excessive production of those cytoactive substances in immunostimulated microglia is generally assumed to be deleterious to neurons and has been suggested in the pathophysiology of several neurodegenerative diseases such as Alzheimer's disease (AD), traumatic brain injury, multiple sclerosis (MS), Parkinson's disease (PD), and more (McGeer et al., 2002; 
Mrak and Griffin, 2007), which gave microglia the position of the central regulators of pathogenesis process of various neurodegenerative diseases in terms of the modulation of neuroinflammation (Liaudet et al., 2000). Therefore inhibition of microglial activation could be a plausible way to modulate neuronal cell death and injury in the progression of the neurodegenerative diseases.

Lipopolysaccharide (LPS) is a cell wall component of Gram negative bacteria, which has been widely used as an experimental tool to activate microglial cells, which resulted in the production of nitric oxide (NO), an important intra- and intercellular signaling molecule involved in the regulation of diverse physiological and pathological mechanisms in cardiovascular, nervous and immunological systems (Shen et al., 2005; Brown, 2007; Weinstein et al., 2008). The production of NO is catalyzed by nitric oxide synthases (NOSs): endotherial NOS (eNOS), inducible NOS (iNOS), and neuronal NOS (nNOS). The iNOS is not present in high concentration in resting cells but could be induced by multiple cytokines as well as by infection. The excessive production of NO by iNOS works as a pro-inflammatory effector of the immune system as well as a cytotoxic agent in various pathogenesis processes (McLaughlin et al., 2006; Prestes-Carneiro et al., 2007).

In addition to iNOS, LPS-stimulation induces the expression of matrix metalloproteinases (MMPs) that are a family of zinc-dependent endopeptidases critical for the digestion of extracellular matrix (ECM). In the central nervous system, neurons and glia including oligodendrocytes, astrocytes and microglia produce MMPs (Yong et al., 1998), which have been implicated in the migration of neural precursors to the site of neurotrauma (Andjelkovic et al., 1998), oligodendrocytes-mediated myelination process (Uhm et al., 1998; Oh et al., 1999) as well as the acceleration of the outgrowth of neurite by digesting chondroitin sulfate proteoglycan that inhibits neurite outgrowth (Zuo et al., 1998). MMPs also participate in the pathogenesis process of several CNS diseases such as multiple sclerosis (MS), Alzheimer's disease (AD) and malignant glioma. For example, MMPs have been suggested to be crucial for leukocyte recruitment, blood-brain barrier (BBB) breakdown (Asahi et al., 2001), myelin destruction (Gijbels et al., 1993) and release of disease-promoting cytokines in inflammatory demyelinating diseases such as MS and Guillain-Barre syndrome. It has been also suggested that MMPs are upregulated in ischemia, which may underlie neural destruction observed in ischemic brain.

C. japonica is an oriental herb with anti-inflammatory characteristics, which has been used in traditional medicine (Otsuka et al., 1981). For example, in periodental
$\mathrm{OC} 2$ and $\mathrm{KB}$ cells, treatment of berberine (BR), an alkaloid in C. japonica (Fukuda et al., 1999), reduced the level of cyclooxygenase-II enzyme and prostaglandin E-2 production (Lee et al., 2003). 13-methylberberine and 13-ethylberberine also inhibited NO production in LPS-stimulated macrophages. Moreover, we reported that the neural injury induced by cerebral ischemia was significantly reduced by Hwangryun-Hae-Dok-tang, an oriental medicine containing $C$. japonica as an essential ingredients. In HwangryunHae-Dok-Tang, Hwangryun means C. japonica, while HaeDok means de-toxification (Hwang et al., 2002). Taken together, above results indicate that components of $C$. japonica would be modulators of the microglial activation as well as neuroinflammatory phenotype in various neurological diseases. At present, information about the possible anti-inflammatory role of $C$. japonica alkaloids in brain is scarce except BR. In the present study, we examined whether $C$. japonica alkaloids have an inhibitory effect in activated microglial BV2 cells.

\section{MATERIALS AND METHODS}

\section{Materials}

All four $C$. japonica compounds used in this study, i.e. palmatine (PL), epi-berberine (EB), coptisine (CP) and BR were dissolved in $0.01 \%$ DMSO (Sigma, St. Louis, MO). These compounds were kindly supplied by the National Center for Standardization of Herbal Medicine (Seoul, Korea). The chemical structure of $C$. japonica alkaloids
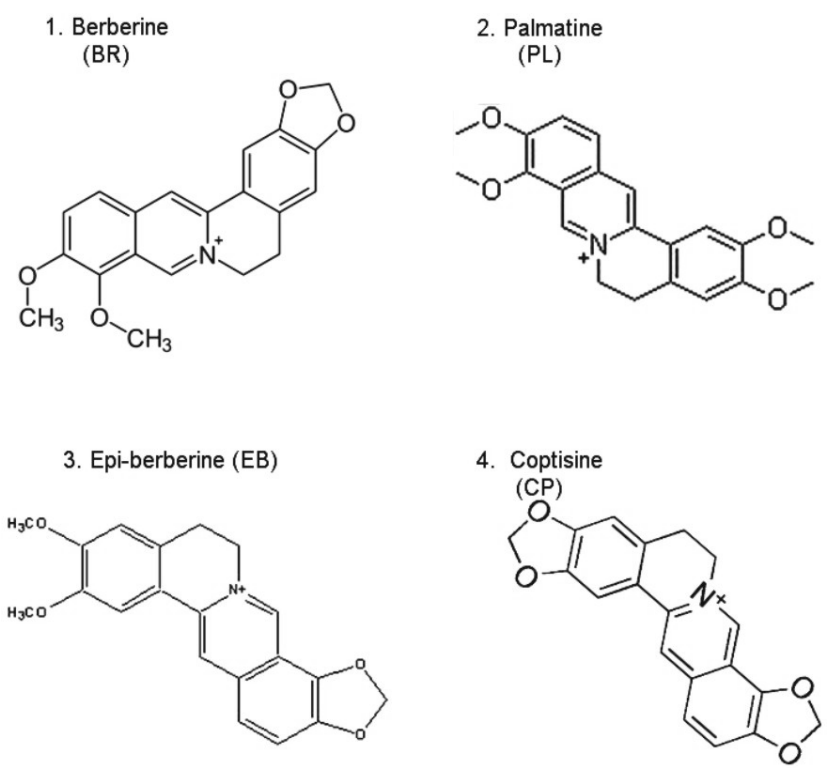

Fig. 1. The Chemical structure of $C$. japonica alkaloids. 
was shown in Fig. 1. Lipopolysaccharide (LPS) (026:B6) was purchased from Sigma (St. Louis, MO). Glucose-free DMEM and fetal bovine serum were from Gibco BRL (Grand Island, NY). Reagents for transfection including lipofectamine $\mathbf{2 0 0 0}$ were obtained from Invitrogen (Carlsbad, CA). Luciferase activity assay kit was purchased from Promega (Madison, WI). All other reagents were obtained from Sigma (St. Louis, MO).

\section{Cell culture and treatment}

The microglial BV2 cell line was grown and maintained in DMEM supplemented with $10 \%$ heat-inactivated FBS, $100 \mathrm{units} / \mathrm{ml}$ penicillin and $100 \mu \mathrm{g} / \mathrm{ml}$ streptomycin at $37^{\circ} \mathrm{C}$ in a humidified incubator under $5 \% \mathrm{CO}_{2}$. For experiments, cells were washed three times with warm DMEM and then added with serum-free medium. Cells were treated with LPS $(0.2 \mu \mathrm{g} / \mathrm{ml})$ alone or in combination with $C$. japonica alkaloids.

\section{Cell viability}

Cell viability was determined in BV2 cell line by MTT reduction assay. In brief, cells were added with MTT dye (10 $\mathrm{mg} / \mathrm{ml}$ in PBS, final concentration of $5 \mu \mathrm{g} / \mathrm{ml}$ ) and incubated for $20 \mathrm{~min}$ at $37^{\circ} \mathrm{C}$ in lightproof condition. The reduction of MTT dye in living cell produces formazan compounds. After resolving the formazan compounds with $100 \% \mathrm{EtOH}$, the absorbance at $590 \mathrm{~nm}$ was measured using a microplate reader (TECAN, Austria).

\section{Measurement of intracellular ROS production}

Total ROS production was determined by DCF fluorescence assay as described previously (Choi et al., 2004). BV2 microglial cells were loaded with 2,7-dihydrodichlorofluorescein diacetate $\left(\mathrm{H}_{2} \mathrm{DCF}-\mathrm{DA}, 5 \mu \mathrm{g} / \mathrm{ml}\right)$ in PBS for $10 \mathrm{~min}$ and then rinsed with the same solution. After 30 min incubation at $37^{\circ} \mathrm{C}$ in the dark, the fluorescence of DCF was measured at an excitation wavelength of $485 \mathrm{~nm}$ and emission wavelength of $535 \mathrm{~nm}$ (slit widths 20 and 25 $\mathrm{nm}$, respectively) using a fluorescence microplate reader (TECAN, Austria). $\mathrm{H}_{2}$ DCF-DA diffuses through cell membranes and is subsequently deacetylated by enzymatic reaction of intracellular esterases to the non-fluorescent DCF-H. Oxidants such as $\mathrm{ONOO}^{-}$effectively convert DCF-H to the highly fluorescent. Fluorescence intensities were corrected for autofluorescence i.e., fluorescence of cells not loaded with $\mathrm{H}_{2}$ DCF-DA.

\section{Determination of NO}

NO production from the LPS-stimulated cells was determined by measuring nitrite, a stable oxidation product of
NO. In brief, nitrite levels were determined by adding the Griess reagent (mixing equal volumes of $0.1 \%$ napthylethylenediamine dihydrochlroride and $1 \%$ sulfanilamide in $5 \%$ phosphoric acid). After $10 \mathrm{~min}$, the absorbance at 540 $\mathrm{nm}$ was determined using an UV spectrophotometer (Beckman DU-650, Fullerton, CA).

\section{Gelatin zymography}

Zymography was performed for semi-quantitative analysis of MMPs levels secreted into the culture medium. In brief, samples were mixed with $5 \mu \mathrm{l}$ of $4 \times$ SDS sample buffer ( $8 \%$ w/v SDS, $40 \%$ glycerol, $200 \mathrm{mM}$ Tris-HCl, pH 6.8, and $0.02 \%$ bromophenol blue) in the absence of a reducing agent and resolved by electrophoresis at $180 \mathrm{~V}$ for $1 \mathrm{~h}$ on $8 \%$ polyacrylamide gel containing $0.1 \%$ SDS and gelatin (from porcine skin, Sigma) at a final concentration of $1 \mathrm{mg} / \mathrm{ml}$. Thereafter, gels were washed twice in $2.5 \%$ Triton X-100 for 30 min each to remove the SDS and then incubated for $24 \mathrm{~h}$ at $37^{\circ} \mathrm{C}$ in reaction buffer $(20 \mathrm{mM}$ Tris- $\mathrm{HCl}, 166 \mathrm{mM} \mathrm{CaCl}_{2}, \mathrm{pH}$ 7.6). After staining the gel with $0.1 \%$ Coomassie Brilliant Blue R-250, gelatinolytic activities were visualized as a clear band in the uniformly stained background. The molecular weight of the MMPs was estimated by comparing the migration distance of the clear bands with the distance migrated by markers of known molecular weight (Gibco BRL, Grand Island, NY).

\section{Western blot}

Cell extracts were prepared with $100 \mu$ of $2 \times$ sample buffer (4\% w/v SDS, $20 \%$ glycerol, $200 \mathrm{mM}$ DTT, $0.1 \mathrm{M}$ Tris-HCl, pH 6.8, and $0.02 \%$ bromophenol blue). The samples were separated by $10 \%$ SDS-PAGE gel electrophoresis and electrically transferred to nitrocellulose (NC) membranes. The NC membranes were blocked with $5 \%$ Blotto and then incubated at $4^{\circ} \mathrm{C}$ for overnight with primary antibodies against phospho-Erk1/2 or total Erk2 (Cell Signaling Technology, Beverly, MA, USA ) which were diluted $1: 3,000$ in $5 \%$ Blotto (Santa Cruz Biotechnology Inc., Santa Cruz, CA), and anti-Nitric Oxide Synthase II (Chemicon International, Temecula, CA, U.S.A.) diluted 1:10,000 in $5 \%$ Blotto. After three times washing with PBS containing $0.2 \%$ Tween-20 (PBS-T), the NC membranes were incubated with peroxidase-labeled goat anti-mouse IgG for pERK and peroxidase-labeled goat-anti-rabbit for iNOS or total Erk2 at room temperature for $2 \mathrm{~h}$. After extensive washing with PBS-T, the membranes were developed by enhanced chemiluminescence (Amersham, Buckinghampshire, UK). As loading controls, Western blot was performed using antibodies against $\beta$-actin in 1:30,000 dilution (Sigma). 
Table. I. Sequences of primers for RT-PCR and expected size of products

\begin{tabular}{|c|c|c|c|}
\hline & MMP-9 & iNOS & GAPDH \\
\hline $\begin{array}{l}\text { Forward } \\
\text { Primer }\end{array}$ & $\begin{array}{l}\text { 5'-TAAGGTATTCAGTTACTCCTA- } \\
\text { CTGGAA-3' }\end{array}$ & $\begin{array}{l}\text { 5'-CAAGAGTTTGACCAGAGGA- } \\
\text { CC-3' }\end{array}$ & 5'-TCCСTCAAGATTGTCAGCAA-3' \\
\hline $\begin{array}{l}\text { Reverse } \\
\text { Primer }\end{array}$ & $\begin{array}{l}\text { 5'-CCTCTCTAGCACACATGCAC- } \\
\text { TT-3' }\end{array}$ & $\begin{array}{l}\text { 5'-TGGAACCACTCGTACTTGG- } \\
\text { GA-3' }\end{array}$ & 5'-AGATCCACAACGGATACATT-3' \\
\hline $\begin{array}{l}\text { Expected size } \\
\text { of PCR } \\
\text { products }\end{array}$ & 324 bp & $654 \mathrm{bp}$ & $308 \mathrm{bp}$ \\
\hline
\end{tabular}

\section{Semiquantitative reverse transcription (RT)-PCR}

Total RNA was extracted from BV2 microglial cells using Trizol reagent (GibcoBRL, Grand Island, NY) according to the manufacturer's protocol. Reverse transcription was performed for $60 \mathrm{~min}$ at $45^{\circ} \mathrm{C}$ with $1 \mu \mathrm{g}$ of total RNA using Maxime RT PreMix Kit (iNtRON Biotechnology, Seoul) according to the manufacturer's protocol. Oligo (dT) $)_{15}$ was used as a primer for this reaction. The samples were then heated at $94^{\circ} \mathrm{C}$ for $5 \mathrm{~min}$ to terminate the reaction. The cDNA obtained from $0.5 \mu \mathrm{g}$ of total RNA was used as a template for PCR amplification of MMP-9 (accession number NM_031055) , iNOS (accession number U03699) and glyceraldehyde 3-phosphate dehydrogenase (GAPDH, accession number M17701) mRNA. Sequences of primers for RT-PCR and the expected size of products were shown in Table I.

PCR mixture contained 1 pmol of each forward and reverse primer and $5 \mu \mathrm{l}$ of each cDNA and Maxime PCR PreMix Kit (i-Taq, iNtRON Biotechnology). For amplification, the following PCR incubation times were used: $94^{\circ} \mathrm{C}$ for $5 \mathrm{~min}$ followed by 28 cycles of $94^{\circ} \mathrm{C}$ for $30 \mathrm{~s}, 55^{\circ} \mathrm{C}$ for $30 \mathrm{~s}, 72^{\circ} \mathrm{C}$ for $1 \mathrm{~min}$, and continued to the final extension step for $10 \mathrm{~min}$ at $72^{\circ} \mathrm{C}$. The amplified PCR products were electrophoresed and analyzed on 1\% agarose-gel. For comparison, PCR products for housekeeping gene, GAPDH, were also performed.

\section{Transient transfection and MMP-9 reporter assay}

BV2 microglial cells were co-transfected with MMP-9 promoter luciferase reporter plasmid and pCMV- $\beta$-galactosidase reporter plasmid using Lipofectamine 2000 reagent according to the manufacturer's protocol as described previously. Next day, BV2 microglial cells were pretreated with $C$. japonica alkaloids $(20 \mu \mathrm{M}) 20 \mathrm{~min}$ before LPS $(0.2 \mu \mathrm{g} / \mathrm{ml})$ treatment in serum-free DMEM. Cells were harvested and assayed for luciferase and $\beta$-galactosidase activities by using the luciferase and $\beta$-galactosidase enzyme assay kits (Promega, Madison, WI), respectively. Luciferase activity was normalized with the $\beta$ - galactosidase activity in the cell lysates.

\section{Statistical analysis}

Data are expressed as the mean \pm standard error of mean (S.E.M) and analyzed for statistical significance by using one way analysis of variance (ANOVA) followed by Newman-Keuls test as a post hoc test and a $p$ value $<$ 0.05 was considered significant.

\section{RESULTS}

\section{Effects of $C$. japonica alkaloids on cell viability of BV2 microglial cells}

We first examined whether alkaloids from $C$. japonica affects BV2 cell viability in our culture condition. In a preliminary experiment, we found that most of the alkaloids we used in this study did not show direct cell toxicity up to $50 \mu \mathrm{M}$ concentration (data are not shown). Thereafter, we used $20 \mu \mathrm{M}$ alkaloids throughout the study. BV2 microglial cells were stimulated with LPS $(0.2 \mu \mathrm{g} / \mathrm{ml})$ for $24 \mathrm{~h}$, when maximal stimulation of BV2 cells was observed, in the absence or presence of $C$. japonica alkaloids and cytotoxicity was measured by MTT reduction assay. All three alkaloids used in this study, i.e. PL, EB and CP did not show significant cytotoxicity in LPS-stimulated BV2 cells (Fig. 2). In contrast, BR showed significant cell toxicity and was excluded in other experiments.

\section{Effects of $C$. japonica alkaloids on ROS generation in LPS-stimulated microglia}

We next determined the effects of $C$. japonica alkaloids on LPS-induced intracellular ROS generation using DCFDA fluorescence methods (Fig. 3). LPS treatment increased total ROS production by 2.3 fold as compared with control. PL pretreatment reduced ROS generation by $52.1 \%$ compared to the LPS-stimulated cells. In addition, EB and CP inhibited intracellular ROS generation mediated by LPS treatment. 


\section{Effects of $C$. japonica alkaloids on LPS-stimulated NO production and iNOS mRNA and protein level in BV2 cells}

It has been relatively well known that LPS induced iNOS expression and NO production in glial cells, which was confirmed in this study. LPS $(0.2 \mu \mathrm{g} / \mathrm{ml})$ increased NO pro-

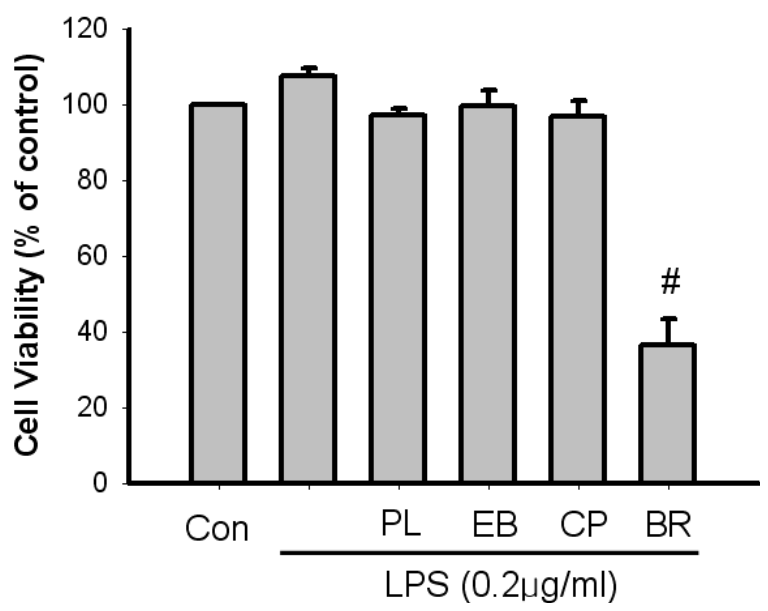

Fig. 2. Effect of $C$. japonica alkaloids on BV2 cell viability. BV2 cells were pretreated with $20 \mu \mathrm{M}$ alkaloids as indicated, followed by stimulation with LPS $(0.2 \mu \mathrm{g} / \mathrm{ml})$ for $24 \mathrm{hrs}$. MTT assay was performed as indicated in materials and methods. Values represent mean \pm SEM of three independent experiments (\# indicates significant decrease compared with control; ${ }^{\#} p<0.05$ vs. LPS treatment). duction in BV2 microglial cells (Fig. 4A). The increase in NO production was preceded by iNOS mRNA and protein

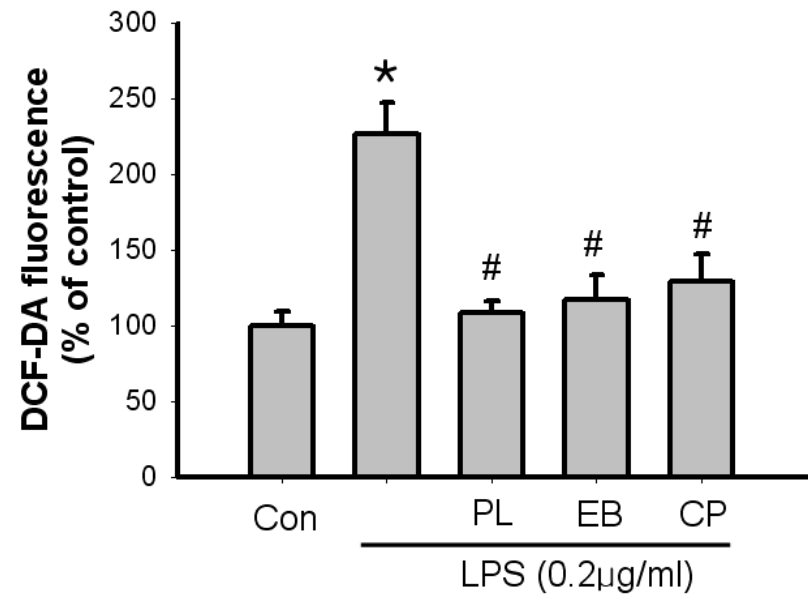

Fig. 3. Inhibitory effect $C$. japonica alkaloids on intracellular ROS production. BV2 cells were pretreated with $20 \mu \mathrm{M}$ alkaloids as indicated, followed by stimulation with LPS $(0.2$ $\mu \mathrm{g} / \mathrm{ml}$ ) for $18 \mathrm{hrs}$. Cells were incubated with $5 \mu \mathrm{M}$ DCF for 0.5 hrs and washed to remove the fluorescent dye. Fluorescence was measured using a fluorescence microplate reader and expressed as percentage increase compared with that of the control. Values represent mean \pm SEM of three independent experiments ( ${ }^{*}$ indicates significant increase compared with control; \# indicates significant decrease compared with LPS alone treated group, $p<0.05$ ).

\section{A. NO Assay}

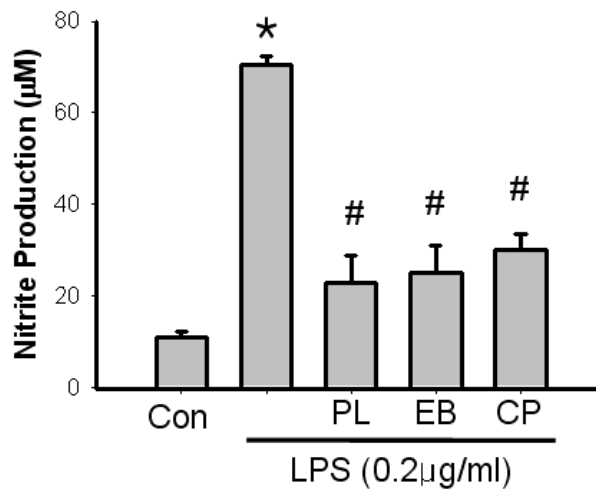

C. iNOS Western blot

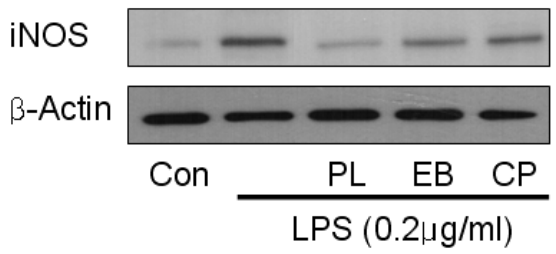

\section{B. iNOS RT-PCR}

iNOS
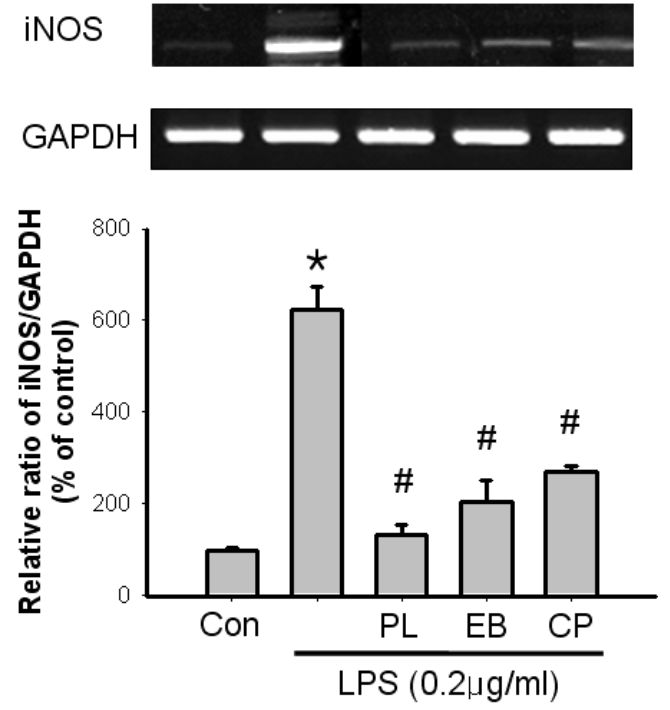

Fig. 4. Inhibition of NO (A), iNOS mRNA (B), and protein (C) expression by $C$. japonica alkaloids in LPS-stimulated BV2 cells. BV2 cells were pretreated with the alkaloids as indicated, followed by immunostimulation with LPS $(0.2 \mu \mathrm{g} / \mathrm{ml})$ for 18 hrs. (A) Cell-conditioned supernatants were collected and NO production was measured using Griess reagent. (B) Levels of iNOS mRNA were assayed by RT-PCR analysis. The graph represents the ratio of iNOS/GAPDH mRNA from three independent experiments. (C) Levels of iNOS and $\beta$-actin proteins were assayed by Western blot. Values correspond to the mean \pm SEM of three independent experiments ${ }^{*}$ indicates significant increase compared with control; \# indicates significant decrease compared with LPS alone treated group, $p<0.05$ ). 
expression (Fig. 4B, C). The treatment of PL, EB and CP inhibited LPS-stimulated NO production (Fig. 4A). PL re-

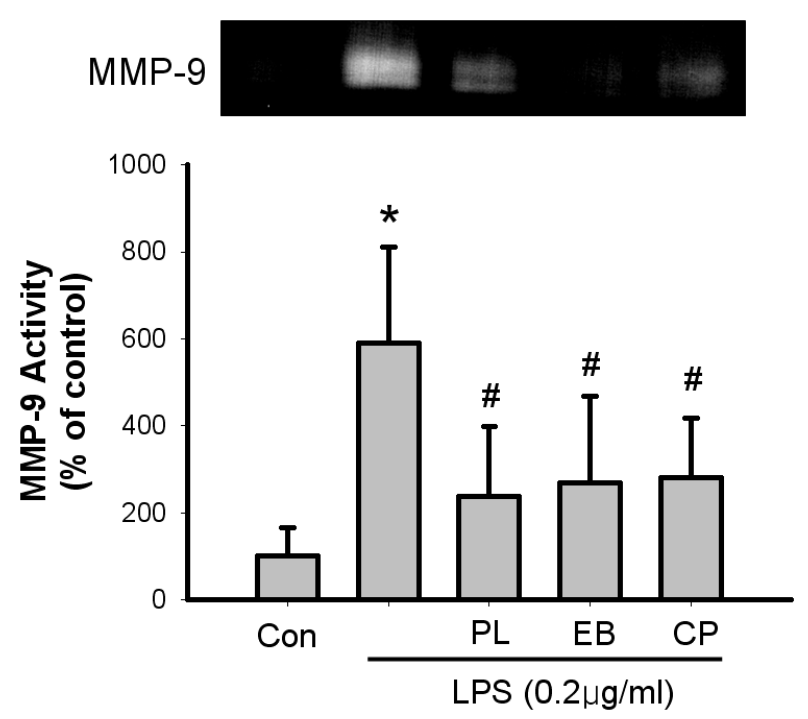

Fig. 5. C. japonica components reduced LPS-induced MMP-9 activity in BV2 Microglia. MMP9 activity was measured from cell-conditioned supernatants by zymography as described in materials and methods. Values correspond to the mean \pm SEM of three independent experiments ( ${ }^{*}$ indicates significant increase compared with control; \# indicates significant decrease compared with LPS alone treated group, $p<0.05$ ). duced LPS-stimulated nitrite production $(23.0 \pm 5.9 \mu \mathrm{M}$, versus $70.4 \pm 1.9$ ), and $E B$ and $C P$ gave similar results $(25.0 \pm 5.9 \mu \mathrm{M}$ and $30.2 \pm 3.3 \mu \mathrm{M}$, respectively, versus $70.4 \pm 1.9$ ). Consistent with above results, co-treatment of C. japonica alkaloids prevented LPS-induced up-regulation of iNOS mRNA as well as proteins (Fig. 4B, C). LPS stimulated the expression of iNOS in BV2 cells by 6.2 fold compared with control, and PL significantly inhibited both iNOS mRNA and protein expression. In addition to PL, EB and $C P$ had inhibitory effect on LPS-induced up-regulation of iNOS mRNA and proteins.

\section{Effects of $C$. japonica alkaloids on LPS-stimulated MMP-9 activity}

Next, we examined whether $C$. japonica alkaloids affect MMP-9 activity, which is another important cytoactive molecules up-regulated in neuroinflammatory condition. As shown in Fig. 5, we measured MMP-9 activity using gelatin zymography. LPS treatment augmented MMP-9 activity in BV2 microglial cells and co-treatment of $C$. japonica components decreased the up-regulation of MMP-9 activity. Consistent with the zymography results, mRNA encoding MMP-9 was up-regulated by LPS treatment in BV2 microglia and co-treatment of $20 \mu \mathrm{M} P L, E B$, and CP inhibited LPS-induced up-regulation of MMP-9 mRNA (Fig. 6A). To verify the effect of alkaloids on MMP-9 expression, we per-

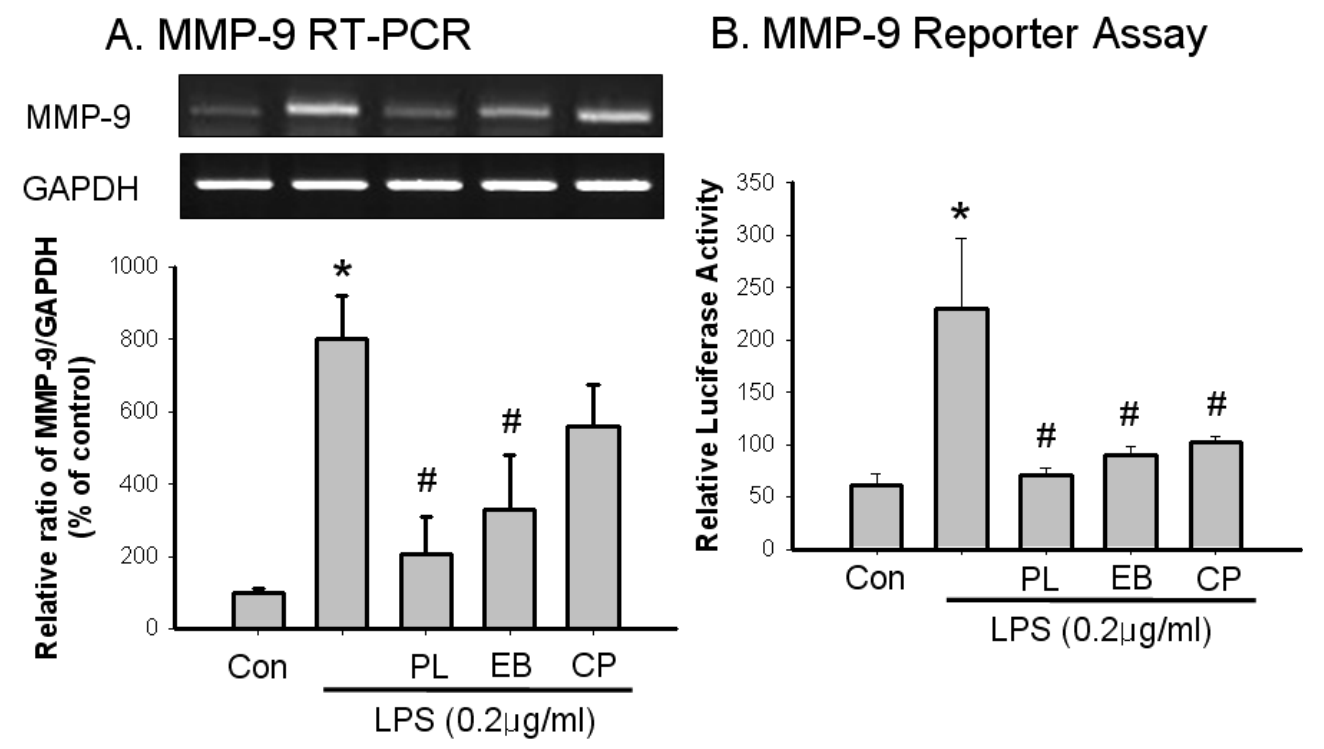

Fig. 6. MMP-9 expression by LPS-stimulated BV2 was inhibited by $C$. japonica alkaloids. (B) BV2 cells were pretreated with $C$. japonica alkaloids $(20 \mu \mathrm{M})$, followed by LPS $(0.2 \mu \mathrm{g} / \mathrm{ml})$ for $24 \mathrm{hrs}$ and levels of MMP-9 and GAPDH mRNA were assayed by RT-PCR analysis. (B) BV2 cells transfected with MMP9 promoter reporter construct were pretreated with C. japonica alkaloids (20 $\mu \mathrm{M})$, followed by LPS $(0.2 \mu \mathrm{g} / \mathrm{ml})$ for $24 \mathrm{hrs}$. The luciferase activity was analyzed as described in the materials and methods. Values represent the mean \pm SEM of three independent experiments. (* indicates significant increase compared with control; \# indicates significant decrease compared with LPS alone treated group, $p<0.05$ ). 
formed MMP-9 promoter luciferase reporter analysis. PL prevented the LPS-induced increase in MMP-9 promoter activity (Fig. 6B), which is consistent with zymography experiments. EB and CP also inhibited MMP-9 promoter activity, although the extent of inhibition was smaller than PL.

\section{Inhibition of Erk1/2 phosphorylation by $C$. japonica alka- loids.}

Several researchers including us reported the essential role of MAPK pathway in the regulation of MMP-9 and iNOS expression in immunostimulated glial cells (Fiebich et al., 2004; Koistinaho et al., 2005; Shin et al., 2007). Therefore, we investigated whether $C$. japonica alkaloids affect ERK1/2 phosphorylation by Western blot. $0.2 \mu \mathrm{g} / \mathrm{ml}$ LPS treatment increased the level of phosphorylated ERK1/2 levels compared with control (2.3 fold, Fig. 7). Co-treatment of PL reduced pERK1/2 level to control levels. Albeit smaller in extent, treatment of EB and CP also decreased $\mathrm{pERK} 1 / 2$ level induced by LPS stimulation. These results suggest that the observed anti-inflammatory effects of C. japonica components on ROS, NO and

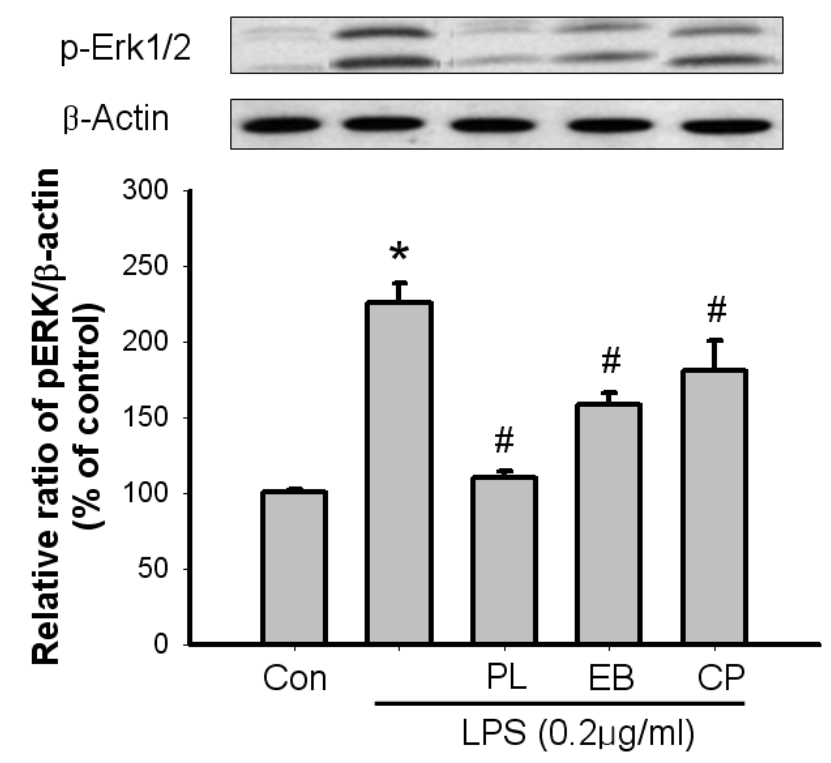

Fig. 7. Inhibition of LPS-induced ERK1/2 phosphorylation by C. japonica alkaloids. BV2 microglial cells were pretreated with C. japonica alkaloids $(20 \mu \mathrm{M}) 20$ min before LPS treatment $(0.2$ $\mu \mathrm{g} / \mathrm{ml}$ ). Cells were harvested $30 \mathrm{~min}$ after LPS treatment and then the level of p-ERK were detected by Western blot. $\beta$-actin was used as loading control. Values represent the mean \pm SEM of $p$-Erk/ $\beta$-actin ratio from three independent experiments (* indicates significant increase compared with control; \# indicates significant decrease compared with LPS alone treated group, $p<0.05$ ).
MMP-9 may be mediated by the inhibition of ERK1/2 phosphorylation.

\section{DISSCUSSION}

In this study, $C$. japonica alkaloids were used to investigate their efficacy under LPS stimulated BV2 cells. C. japonica is a perennial medicinal plant that has anti-inflammatory activity. C. japonica contains numerous biologically active alkaloids including $\mathrm{BR}, \mathrm{PL}, \mathrm{EB}$, and $\mathrm{CP}$ (Park et al., 2003). And among others, C. japonica exhibit anti-inflammatory, sedative, antidotal, and anti-tumor properties, many of which were attributed to BR (Yesilada and Kupeli, 2002). Other alkaloids like PL, EB had inhibitory effect against edema on mouse ear induced by application of 12-O-tetradecanoylphorbol-13-acetate (Yasukawa et al., 1991). In addition, CP showed strong anti-photo-oxidative activity in the chlorophyll-sensitized photo-oxidation of linoleic acid (Kase et al., 1999).

Previously, C. japonica extract and its major component, BR, were reported to have NO-scavenging activity (Yokozawa et al., 2000). NO is synthesized from L-arginine by NOS with NADPH and oxygen. The constitutive NOS such as eNOS and nNOS synthesizes small amount of NO sufficient for wide biological function in regulating physiological processes. However, high concentrations of NO during inflammation and pathological situation have been shown to participate in multiple stages of diseases. The massive generation of $\mathrm{NO}$ following an inflammatory stimulation is attributed by inducible NOS (iNOS). Thus, inhibition of NO generation in inflammatory condition can be achieved by reducing iNOS induction. The inhibitory effects of PL, EB and CP on iNOS induction suggest that these alkaloids are useful to down-regulate NO production in neuroinflammatory condition.

In this study, LPS treatment significantly increased MMP-9 level and activity in BV2 cells. Many investigators reported that activated microglia induced the expression and activity of MMPs (Rosenberg, 2002). In this study, it was revealed that alkaloids such as PL, EB and CP have regulatory roles on MMP-9 activity in activated BV2 microglial cells. All the alkaloids used in this study significantly reduced MMP -9 activity as well as the expression level. MMP-9 activity is related to many neurodegeneration diseases, for example, MS (Cossins et al., 1997), AD (Deb and Gottschall, 1996), PD (Safciuc et al., 2007), and stroke (Bozdagi et al., 2007).

The decrease in MMP activity was attributed to the reduced MMP expression. Up-regulation of MMP-9 mRNA level by LPS was inhibited by $20 \mu \mathrm{M}$ PL, which seems to 
be regulated by transcriptional control (Fig. 6). To verify the transcriptional regulatory mechanism, we used MMP-9 reporter assay, which provided additional support for the transcriptional regulation of MMP-9 mRNA level by C. japonica alkaloids. Actually, the transcriptional control of MMP-9 expression has been reported in a wide variety of cells with different compounds. For instance, polyphenolic compound from Tristaniopsis calobuxus regulated MMP-9 expression level by interacting with promoter region and minocycline inhibited MMP-9 activity on human aortic smooth muscle cell through MMP-9 mRNA reduction (Bellosta et al., 2003; Yao et al., 2004). These results indicate that appropriate use of alkaloids like PL, EB, and CP might be helpful to treat and prevent neuroinflammatory diseases by the down-regulation of MMP-9.

To elicit inflammatory reactions in immune mediator cells like microglia, intracellular signaling pathways linked to transcription factors are activated. These include activation of protein kinases such as protein kinase $C$, phosphoinositide 3-kinase, protein tyrosine kinase, and MAPKs (Erk1/2, p38, SAPK/JNK). Erk1/2 activity, which plays essential roles in the regulation of NO and MMP-9 production, was inhibited by $C$. japonica alkaloids (Fig. 7). How those alkaloids prevent the activation of Erk $1 / 2$ is not clear yet. Considering the role of ROS in the activation of Erk1/2, one plausible explanation is that the inhibition of ROS production from BV2 microglial cells by $C$. japonica alkaloids mediates the observed inhibitory effects on pErk1/2.

Microglia are regarded as primary cell types responsible for inflammation-related neurotoxicity (Liu and Hong, 2003). Like peripheral immune cells, stimulated microglia release neurotoxic mediators, pro-inflammatory cytokines, and free radicals like NO after activation with LPS or interferon- $\gamma$ in vitro. These up-regulated cytokines and mediators such as prostaglandin E2, interleukin-1,6, NO, superoxide anion, and matrix metalloproteinases (MMPs) are thought to be major cause of neuronal injuries and progression of neurodegenerative diseases (Minghetti and Levi, 1998). Activated microglia are commonly observed in injured brain and related with progression of neurodegenerative diseases. The anti-neuroinflammatory effect of $C$. japonica alkaloids may provide additional measure to control microglial activation and neuro-inflammation and the effects of them in the control of neurodegenerative diseases such as stroke, MS, AD, and PD, should be investigated further in the future study.

\section{ACKNOWLEDGMENTS}

This work was supported in part by funds from Korea Food \& Drug Administration and in part by grants from Brain Research Center of the $21^{\text {st }}$ Century Frontier Research Program funded by the Ministry of Science and Technology, the Republic of Korea.

\section{REFERENCES}

Andjelkovic, A. V., Nikolic, B., Pachter, J. S. and Zecevic, N. (1998). Macrophages/microglial cells in human central nervous system during development: an immunohistochemical study. Brain Research 814, 13-25.

Asahi, M., Wang, X., Mori, T., Sumii, T., Jung, J. C., Moskowitz, M. A., Fini, M. E. and Lo, E. H. (2001). Effects of matrix metalloproteinase-9 gene knock-out on the proteolysis of blood-brain barrier and white matter components after cerebral ischemia. J. Neurosci. 21, 7724-7732.

Bellosta, S., Dell'Agli, M., Canavesi, M., Mitro, N., Monetti, M., Crestani, M., Verotta, L., Fuzzati, N., Bernini, F. and Bosisio, E. (2003). Inhibition of metalloproteinase- 9 activity and gene expression by polyphenolic compounds isolated from the bark of Tristaniopsis calobuxus (Myrtaceae). Cell Mol. Life Sci. 60, 1440-1448.

Bozdagi, O., Nagy, V., Kwei, K. T. and Huntley, G. W. (2007). In vivo roles for matrix metalloproteinase- 9 in mature hippocampal synaptic physiology and plasticity. J. Neurophysiol. 98, 334-344.

Brown, G. C. (2007). Mechanisms of inflammatory neurodegeneration: iNOS and NADPH oxidase. Biochemical Society Transactions 35, 1119-1121.

Choi, J. W., Shin, C. Y., Yoo, B. K., Choi, M. S., Lee, W. J., Han, B. H., Kim, W. K., Kim, H. C. and Ko, K. H. (2004). Glucose deprivation increases hydrogen peroxide level in immunostimulated rat primary astrocytes. J. Neuroscience Research 75, 722-731.

Cossins, J. A., Clements, J. M., Ford, J., Miller, K. M., Pigott, R., Vos, W., Van der Valk, P. and De Groot, C. J. (1997). Enhanced expression of MMP-7 and MMP-9 in demyelinating multiple sclerosis lesions. Acta. Neuropathologica. 94, 590-598.

Cunningham, C., Wilcockson, D. C., Campion, S., Lunnon, K. and Perry, V. H. (2005). Central and systemic endotoxin challenges exacerbate the local inflammatory response and increase neuronal death during chronic neurodegeneration. J. Neurosci. 25, 9275-9284

Deb, S. and Gottschall, P. E. (1996). Increased production of matrix metalloproteinases in enriched astrocyte and mixed hippocampal cultures treated with beta-amyloid peptides. $J$. Neurochemistry 66, 1641-1647.

Fiebich, B. L., Akundi, R. S., Lieb, K., Candelario-Jalil, E., Gmeiner, D., Haus, U., Muller, W., Stratz, T. and Munoz, E. (2004). Antiinflammatory effects of 5-HT3 receptor antagonists in lipopolysaccharide-stimulated primary human monocytes. Scandinavian J. Rheumatology 28-32.

Fukuda, K., Hibiya, Y., Mutoh, M., Koshiji, M., Akao, S. and Fujiwara, H. (1999). Inhibition of activator protein 1 activity by berberine in human hepatoma cells. Planta. Medica. 65, 
381-383

Gijbels, K., Proost, P., Masure, S., Carton, H., Billiau, A. and Opdenakker, G. (1993). Gelatinase B is present in the cerebrospinal fluid during experimental autoimmune encephalomyelitis and cleaves myelin basic protein. J. Neuroscience Research 36, 432-440.

Hwang, Y. S., Shin, C. Y., Huh, Y. and Ryu, J. H. (2002). Hwangryun-Hae-Dok-tang (Huanglian-Jie-Du-Tang) extract and its constituents reduce ischemia-reperfusion brain injury and neutrophil infiltration in rats. Life Sciences 71, 21052117.

Kase, Y., Saitoh, K., Makino, B., Hashimoto, K., Ishige, A. and Komatsu, Y. (1999). Relationship between the antidiarrhoeal effects of Hange-Shashin-To and its active components. Phytother. Res. 13, 468-473.

Koistinaho, M., Malm, T. M., Kettunen, M. I., Goldsteins, G., Starckx, S., Kauppinen, R. A., Opdenakker, G. and Koistinaho, J. (2005). Minocycline protects against permanent cerebral ischemia in wild type but not in matrix metalloprotease-9-deficient mice. J. Cereb. Blood Flow Metab. 25 460-467.

Lee, D. U., Kang, Y. J., Park, M. K., Lee, Y. S., Seo, H. G., Kim, T. S., Kim, C. H. and Chang, K. C. (2003). Effects of 13alkyl-substituted berberine alkaloids on the expression of COX-II, TNF-alpha, iNOS, and IL-12 production in LPSstimulated macrophages. Life Sciences 73, 1401-1412.

Liaudet, L., Soriano, F. G. and Szabo, C. (2000). Biology of nitric oxide signaling. Critical Care Medicine 28, N37-52.

Liu, B. and Hong, J. S. (2003). Role of microglia in inflammationmediated neurodegenerative diseases: mechanisms and strategies for therapeutic intervention. J. Pharmacology and Experimental Therapeutics 304, 1-7.

Majumdar, A., Cruz, D., Asamoah, N., Buxbaum, A., Sohar, I., Lobel, P. and Maxfield, F. R. (2007). Activation of microglia acidifies lysosomes and leads to degradation of Alzheimer amyloid fibrils. Molecular Biology Cell 18, 1490-1496.

McGeer, P. L., Yasojima, K. and McGeer, E, G. (2002). Association of interleukin-1 beta polymorphisms with idiopathic Parkinson's disease. Neuroscience Letters 326, 67-69.

McLaughlin, P., Zhou, Y., Ma, T., Liu, J., Zhang, W., Hong, J. S., Kovacs, M. and Zhang, J. (2006). Proteomic analysis of microglial contribution to mouse strain-dependent dopaminergic neurotoxicity. Glia. 53, 567-582.

Minghetti, L. and Levi, G. (1998). Microglia as effector cells in brain damage and repair: focus on prostanoids and nitric oxide. Progress in Neurobiology 54, 99-125.

Mrak, R. E. and Griffin, W. S. (2007). Common inflammatory mechanisms in Lewy body disease and Alzheimer disease. J. Neuropathology and Experimental Neurology 66, 683686.

Oh, L. Y., Larsen, P. H., Krekoski, C. A., Edwards, D.R., Donovan, F., Werb, Z. and Yong, V. W. (1999). Matrix metalloproteinase-9/ gelatinase $B$ is required for process outgrowth by oligodendrocytes. J. Neurosci. 19, 8464-8475.

Otsuka, H., Fujimura, H., Sawada, T. and Goto, M. (1981). [Studies on anti-inflammatory agents. II. Anti-inflammatory constituents from Rhizome of Coptis japonica Makino (author's transl)]. Yakugaku. Zasshi. 101, 883-890.

Park, H., Kim, M. S., Jeon, B. H., Kim, T. K., Kim, Y. M., Ahnn, J., Kwon, D. Y., Takaya, Y., Wataya, Y. and Kim, H.S.
(2003). Antimalarial activity of herbal extracts used in traditional medicine in Korea. Biological \& Pharmaceutical Bulletin 26, 1623-1624.

Perry, V. H. and Gordon, S. (1988). Macrophages and microglia in the nervous system. Trends in Neurosciences 11, 273277.

Prestes-Carneiro, L. E., Shio, M. T., Fernandes, P. D. and Jancar, S. (2007). Cross-regulation of iNOS and COX-2 by its products in murine macrophages under stress conditions. Cell Physiol. Biochem. 20, 283-292.

Rosenberg, G. A. (2002). Matrix metalloproteinases in neuroinflammation. Glia. 39, 279-291.

Safciuc, F., Constantin, A., Manea, A., Nicolae, M., Popov, D. Raicu, M., Alexandru, D. and Constantinescu, E. (2007). Advanced glycation end products, oxidative stress and metalloproteinases are altered in the cerebral microvasculature during aging. Current Neurovascular Research 4, 228234.

Shen, S., Yu, S., Binek, J., Chalimoniuk, M., Zhang, X., Lo. S. C., Hannink. M., Wu, J., Fritsche, K., Donato, R. and Sun, G. Y. (2005). Distinct signaling pathways for induction of type II NOS by IFNgamma and LPS in BV-2 microglial cells. Neurochemistry International 47, 298-307.

Shin, C. Y., Lee, W. J., Choi, J. W., Choi, M. S., Park, G. H. Yoo, B. K., Han, S. Y., Ryu, J. R., Choi, E. Y. and Ko, K. H. (2007). Role of p38 MAPK on the down-regulation of matrix metalloproteinase- 9 expression in rat astrocytes. Archives of Pharmacal Research 30, 624-633.

Uhm, J. H., Dooley, N. P., Oh, L. Y. and Yong, V. W. (1998). Oligodendrocytes utilize a matrix metalloproteinase, MMP-9, to extend processes along an astrocyte extracellular matrix. Glia. 22, 53-63.

Weinstein, J. R., Swarts, S., Bishop, C., Hanisch, U. K. and Moller, T. (2008). Lipopolysaccharide is a frequent and significant contaminant in microglia-activating factors. Glia. 56, $16-26$

Yao, J. S., Chen, Y., Zhai, W., Xu, K., Young, W. L. and Yang, G. Y. (2004). Minocycline exerts multiple inhibitory effects on vascular endothelial growth factor-induced smooth muscle cell migration: the role of ERK $1 / 2, \mathrm{PI} 3 \mathrm{~K}$, and matrix metalloproteinases. Circulation Research 95, 364-371.

Yasukawa, K., Takido, M., Ikekawa, T., Shimada, F., Takeuchi, M. and Nakagawa, S. (1991). Relative inhibitory activity of berberine-type alkaloids against 12-O-tetradecanoylphorbol-13-acetate-induced inflammation in mice. Chemical \& Pharmaceutical Bulletin 39, 1462-1465.

Yesilada, E. and Kupeli, E. (2002). Berberis crataegina DC. root exhibits potent anti-inflammatory, analgesic and febrifuge effects in mice and rats. J. Ethnopharmacology 79, 237-248.

Yokozawa, T., Chen, C. P. and Tanaka, T. (2000). Direct scavenging of nitric oxide by traditional crude drugs. Phytomedicine 6, 453-463.

Yong, V. W., Krekoski, C. A., Forsyth, P. A., Bell, R., Edwards, D. R. (1998). Matrix metalloproteinases and diseases of the CNS. Trends in Neurosciences 21, 75-80.

Zuo, J., Hernandez, Y. J. and Muir, D. (1998). Chondroitin sulfate proteoglycan with neurite-inhibiting activity is upregulated following peripheral nerve injury. J. Neurobiology $34,41-54$. 